\section{"Safe Marriages" for Thalassaemia Prevention: A KAP Survey in Sri Lanka}

\section{Abstract}

Thalassemia is the commonest single gene disorder in Sri Lanka. Government sponsored palliative care accumulate caseload leading to escalation of the health budget. Therefore prevention has become mandatory. Lack of facilities for antenatal diagnosis and the legal sanctions of abortions kept the nation away from adopting the policy of terminating the affected pregnancies which is the wellestablished method of thalassemia prevention in many parts of the world. National thalassemia prevention program adopted a policy of "safe marriage" that is defined as a marriage where at least one of the partners in a couple is not a carrier for thalassemia. This survey was conducted to evaluate the outcomes of the project after one year. Results show very poor uptake in spite of free facilities available for screening and counseling and reasonable awareness about the concept among the public. More intensive monitoring and strengthening of education programs are recommended. Establishing and integrating the thalassemia prevention program in the excising health care delivery should be intensified while considering the need for implementing a compulsory screening and counseling program in the country.

Keywords: Thalassemia prevention; Premarital screening; Safe marriages

Received: Sep 24, 2015, Accepted: Oct 24, 2015, Published: Oct 26, 2015

\section{Mudiyanse RM ${ }^{1}$, Senanayake MP² and Rathnayake RMS ${ }^{3}$}

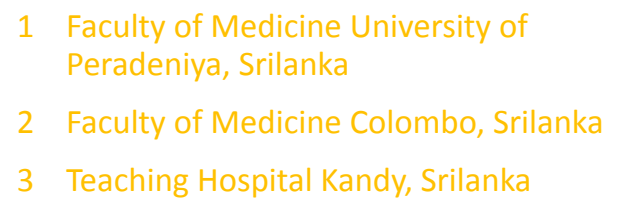

Corresponding author:

Rasnayaka Mudiyanse

rasnayakamudiyanse@gmail.com

Faculty of Medicine University of Peradeniya, Paediatrics, Peradeniya, 20 Nelum Mawatha, Prime Rose Garden Kandy, Kandy, Sri Lanka 0094, Sri Lanka.

Tel: 0094812222900,0094777844220

Fax: 0094812222900

Citation: Mudiyanse RM, Senanayake MP, Rathnayake RMS. "Safe Marriages" for Thalassaemia Prevention: A KAP Survey in Sri Lanka. Transl Biomed. 2015, 6:3.

\section{Introduction}

Beta-thalassemia is the commonest serious single gene disorder in Sri Lanka. The psychosocial and financial burden placed on affected persons and families is heavy, as is the cost of treatment to health services which exceeds Rupees 1.5 billion annually for a national caseload of approximately 5000 patients [1-4]. Preventing this hereditary disorder is therefore a priority.

Screening programs were an essential component of preventive strategies in countries that effectively reduced birth prevalence of beta thalassemia $[5,6]$. With termination of pregnancy not legally permissible in Sri Lanka, prenatal diagnosis and selective abortion is not possible. Instead, the concept of "safe marriages" has been adopted; a "safe marriage" is defined as a union where (at least) one partner is not a carrier [7].

This strategy involves voluntary community participation for premarital screening of carrier status. Emulating astrological consultation undertaken to assess compatibility of marriage partners, a cultural practice widely used in the region, this new strategy enabled individuals to make informed decisions that would reduce "at-risk" marriages and giving birth to affected offspring. The community based health education program used pictorial depiction of non-compatibility of carrier-carrier marriages as well as carrier marriages with those who have not tested in a similar manner to an astrological tables (Figure 1).

In Sri Lanka, voluntary teenage screening is recommended for persons from the age of 15 years. The test result is issued as a colour coded card denoting carrier status (pink if positive, green if negative) [7]. Two and a half years after the initiation of the program, this survey was carried out this survey on knowledge, attitude and practices regarding this program in the district which has the highest thalassemia prevalence (Kurunegala). The literacy rate within the district is comparable to the rest of the country.

\section{Method}

After obtaining approval from Ethical Committee, Faculty of Medicine Colombo, an educational and motivational seminar on prevention of thalassemia was held for Registrars of Marriages (RoM) of the Kurunegala District. From a total of 112 attending RoM, twenty-two (one out of five) were randomly selected to represent the entire North Western province. Eighteen RoMs 
consented to participate as data collectors. All the marriages registered by these RoMs were recruited for the study. Further capacity building was carried out to equip them with necessary skills in gathering sensitive health related details, provision of information and appropriate referral to local health services.

Fifteen item questionnaire was developed at three stages: initial 25 items were pretested among young healthy persons and further refined after focus group discussions with parents having children affected by thalassemia. The final questionnaire was developed after obtaining opinion of the participating RoMs and the questionnaire contained fifteen structured questions on awareness of the disease and the need for screening, acceptability of screening, results of the blood test and perception on premarital screening being made compulsory.

The survey was conducted over a period of four months (1 September 2012 to 31 December 2012) among men and women at the time of giving 'notice of marriage'. An information sheet explained that they were free to not comply with the survey. All men and women who consented to participate were serially enrolled. The pretested questionnaire was handed out and filled in individually and anonymously and returned in a sealed envelope to the RoM by each respondent. The completed questionnaires were stored in pairs under confidential cover, for analysis by the authors. RoM received no remunerations. Awareness of thalassemia disease, screening coverage and proportions of "safe marriages" were calculated.

\section{Results}

Total number of marriages registered in the district over the study period was 4037 . Survey included 425 couples ( 850 respondents) and response rate was $100 \%$.

We found that $684(80 \%)$ of respondents were "aware of the disease thalasasamia and its associated problems". Of these respondents 401 (47\%) claimed to have "adequate knowledge about the illness and its problems" and 283 (33\%) "Wished for more information despite having some knowledge of their illness". A family history of thalassaemia was present in 40 (4.7\%) respondents and $26(3 \%)$ of partners (Table 1). "Screening should be made compulsory" was positively responded to by 654 (77\%) and negatively by a minority of 51 (6\%); with 145 (17\%) not responding to this question. However, premarital screening was considered suitable by $701(82 \%)$ of the total study sample. This opinion had not been influenced by participant's perception about their knowledge.

Total number who had undergone screening was 144 (17\%); and the partner had been tested in 122 (14\%). Although 75\% knew that "a simple blood test could recognize carrier status" 675 (79\%) had not undertaken the screening blood test.

Of the total number screened 74 (51\%) were still awaiting the test results. Seventy (48\%) had received "thalassemia cards": 63 green cards, 7 pink cards.

Four of the seven pink cardholders (thalassemia carriers) were marrying green card holders (normal persons); but three married persons who had not been tested. Of the 63 green cardholders, 44 had partners who also had green cards.
The profile of marriages as per carrier status was: green and green (22), green and untested (15), green and pink (4), pink and untested (3), pink and pink (0) untested and untested (381) indicating that only $41(10.5 \%)$ of the 425 marriages were 'safe marriages'.

By not fulfilling the criteria of a 'safe marriage', 384 (90\%) marriages could be considered 'unsafe' i.e. with the risk of producing children affected with thalassemia.

\section{Discussion}

Thalassemia is an important public health problem in Sri Lanka because of its chronic, incurable nature causing a heavy burden of suffering on families and a large financial cost to health services. Treatment is mostly symptomatic therefore cost escalation is inevitable. Cost of care for managing thalassemia patient is estimated to exceed $5 \%$ of the limited health budget of the country [1]. However establishing a cure with stem cell transplantation is unlikely to be affordable by the vast majority of sufferers even when this service becomes available in Sri Lanka.

Preventing the birth of new cases is considered the best approach for controlling thalassemia for which screening for thalassemia carriers is mandatory. Thalassemia screening can be either voluntary or mandatory, before or after the marriage, and before or after the pregnancy. Several countries like Cyprus, Iran, Saudi Arabia and Palestinian territories have adopted mandatory screening achieving almost $100 \%$ coverage. Other countries have adopted voluntary screening in accordance with the WHO mandate [8]. In all countries thalassemia screening has contributed for reduced incidence of beta thalassemia and carrier screening is an essential intervention in all these preventive programs $[5,6,9]$. Screening of entire populations, high-risk populations, extended families, school children, pregnant mothers and couples before marriage have been carried out as each local situation warranted $[5,6]$. A policy of voluntary screening of school leavers' has been adopted. The screening relies on MCV and $\mathrm{MCH}$ performed by an automated haematological analyzer. Those with MCV above $80 \mathrm{fl}$ and $\mathrm{MCH}$ above 27pg are considered non-carriers and a green card would be given. A qualified medical officer would treat those with MCV less than $80 \mathrm{fl}$ and $\mathrm{MCH}$ less than $27 \mathrm{pg}$ with iron after a comprehensive clinical evaluation. Recovery of MCV and $\mathrm{MCH}$ in repeat test also would be given a green card. Others with persistent $\mathrm{MCV}$ values below $80 \mathrm{fl}$ and $\mathrm{MCH}$ values below $27 p g$ would be referred for HPLC to confirm thalassemia carrier state and they would be given a red card. Results of the blood test would be communicated to people with health education and counseling using the thalassemia porondoma which is a pictorial depiction of the risks of range of combinations of pairs in a proposed couple (Figure 1).

In most communities like Sri Lanka marriage is a complex phenomenon strongly influenced by parents and honorable stakeholders in the family. It may be extremely difficult to convince a couple to give up an agreed marriage proposal due to stigma and social and cultural belief. Therefore teenage screening well before they decide on their partners would be the ideal solution. Parents of thalassemia patients are an underutilized but a strong group of campaigners to promote safe marriage. 
Percentage carrier rate of beta-thalassemia gene in Sri Lanka is reported as $2.2 \%$ [1] The 'safe marriages concept' formed the basis of the National Thalassemia Prevention Program of the Ministry of Health Sri Lanka because selective abortion is illegal as well as unacceptable on religious grounds. Premarital screening was presumed to meet with acceptance due to it being akin to comparison of horoscopes to assess compatibility, a cultural practice widely undertaken prior to marriage in Sri Lanka [7].

The national program depends on voluntary screening of unmarried persons from 15 years onwards. Due to the high disease prevalence the program was launched in 2009 in North Western Province and Kurunegala district in particular.

Number of marriages monitored at the level of RoM provided a specific and crucial indication of the effectiveness of the prevention program. This survey covered one fifth of all RoMs in the identified district. Data was available on over $10 \%$ of all marriages registered during the study period.

Although screening is offered free of charge by the state, only $17 \%$ of the population underwent carrier screening. Only seventy two percent of the study sample was aware of thalassemia. Similar study in Italy records awareness only among $85 \%$ of the study sample [8]. Total lack of awareness in a relatively high percentage (18\%) and approximately $50 \%$ expressing the desire to have more knowledge indicate that greater public education is needed. Countries that have achieved success with prevention of thalassemia have provided genetic counseling on the importance of getting tested, persuasion at individual level and guidance on interpretation of test results $[6,7]$. It is recommend to incorporate thalassemia prevention in the school curriculum as one of the NO cost and most effective intervention. Public awareness programs delivered through print and electronic media are complemented by more intensive educational and counseling programs delivered through public health field staff, general practitioners, and outpatient departments of the government hospitals. Integrating regular monitoring of marriages at the time of registration would not only provide valuable information but also strengthen the prevention program. Making screening compulsory is a strategy that may need serious consideration if screening rates remain low even after these services are in place. As per this survey $77 \%$ were in agreement with compulsory screening. According to a similar survey in Pakistan 95\% of parents $90 \%$ of doctors have endorsed genetic counseling [8]. A previous public survey in Sri
Lanka has documented $96 \%$ of people agreed that at least one person in a couple should undergo screening [8].

Analyzing characteristics such as ethnic, educational or socioeconomic status and their influence on voluntary screening was not a part of this survey. Such an analysis would provide information on religious and cultural influences which are important in developing counseling services sensitive to such issues [6-8].

Experience of other countries suggests that acceptance of preventive strategies improved over time $[10,11]$. The program in Sri Lanka being still in its infancy is perhaps one reason for the low screening rate.

Comprehensive thalassemia prevention programs have been found to be cost effective. Total cost per case prevented was less than the cost of a single year of treatment for a single individual $[12,13]$.

\section{Conclusions}

A mechanism for constant motivation and monitoring should be put in place for thalassemia prevention as has been done for other community based prevention programs. Educational programs should be strengthened further targeting primary health care workers, first contact doctors and all the staff of outpatient departments. Enhancing the current teaching about the scientific basis of thalassemia prevention in school curriculum is underway. However compulsory screening and counseling seems a reasonable policy considering the possible risk of thalassemia carries living in society with high prevalence of thalassemia. Systems of monitoring at regional and national level should include multiple indicators such as thalassemia screening coverage in the community, incidence of at risk marriages, at risk pregnancies and births of new affected cases would be valuable indicators of monitoring the prevention program. Establishing a national thalassemia register and referral center for evaluating complicated problems and cases with borderline $\mathrm{HbA} 2$ values would be an essential steps for future progress.

\section{Acknowledgements}

The services rendered by Registrars of Marriage who gathering data for this ar acknowladhe, for their invaluable assistance. 
Table 1 Opinion of the respondents to the16 item survey questionnaire.

\begin{tabular}{|c|c|c|c|c|c|c|c|}
\hline \multirow[b]{2}{*}{1} & \multirow[b]{2}{*}{ I am aware of the disease thalassemia and its associated problems } & \multicolumn{2}{|c|}{ Yes } & \multicolumn{2}{|c|}{ No } & \multirow{2}{*}{$\begin{array}{c}\text { DK } \\
1\end{array}$} & \multirow{2}{*}{$\begin{array}{c}\text { NR } \\
11\end{array}$} \\
\hline & & 684 & $80 \%$ & 154 & $18 \%$ & & \\
\hline 2 & I have adequate knowledge about the illness and its problems & 401 & $47 \%$ & 405 & $48 \%$ & 30 & 14 \\
\hline 3 & I wish if I have more information about thalassemia & 283 & $33 \%$ & 380 & $45 \%$ & 27 & 160 \\
\hline 4 & I have had a relative affected with thalassemia & 40 & $5 \%$ & 571 & $67 \%$ & 216 & 23 \\
\hline 5 & I have heard about thalassemia trait (carrier state) & 386 & $45 \%$ & 393 & $46 \%$ & 28 & 43 \\
\hline 6 & Thalassemia trait is recognizable by a simple blood test & 638 & $75 \%$ & 126 & $15 \%$ & 57 & 29 \\
\hline 7 & I have had the blood test for thalassemia done on myself & 144 & $17 \%$ & 675 & $79 \%$ & 8 & 23 \\
\hline 8 & I have been informed of what my blood test result is & 70 & $49 \%$ & 69 & $48 \%$ & 3 & 2 \\
\hline 9 & Because of my test result I was given a green card & 63 & - & - & - & - & - \\
\hline 10 & Because of my test result I was given a pink card & 7 & - & - & - & - & - \\
\hline 11 & I have informed my blood test to my prospective spouse & 132 & $16 \%$ & 642 & $76 \%$ & 25 & 51 \\
\hline 12 & My proposed spouse has relative/s with thalassemia & 26 & $3 \%$ & 576 & $68 \%$ & 211 & 37 \\
\hline 13 & My proposed spouse has had the blood test to check for thalassemia & 122 & $14 \%$ & 660 & $78 \%$ & 34 & 34 \\
\hline 14 & My proposed spouse has informed me about his/her thalassemia status & 156 & $18 \%$ & 613 & $72 \%$ & 20 & 61 \\
\hline 15 & I think it is suitable to test blood before the marriage & 701 & $82 \%$ & 74 & $9 \%$ & 45 & 30 \\
\hline 16 & Testing of blood before marriage should be made compulsory & 654 & $77 \%$ & 51 & $6 \%$ & 118 & 27 \\
\hline
\end{tabular}

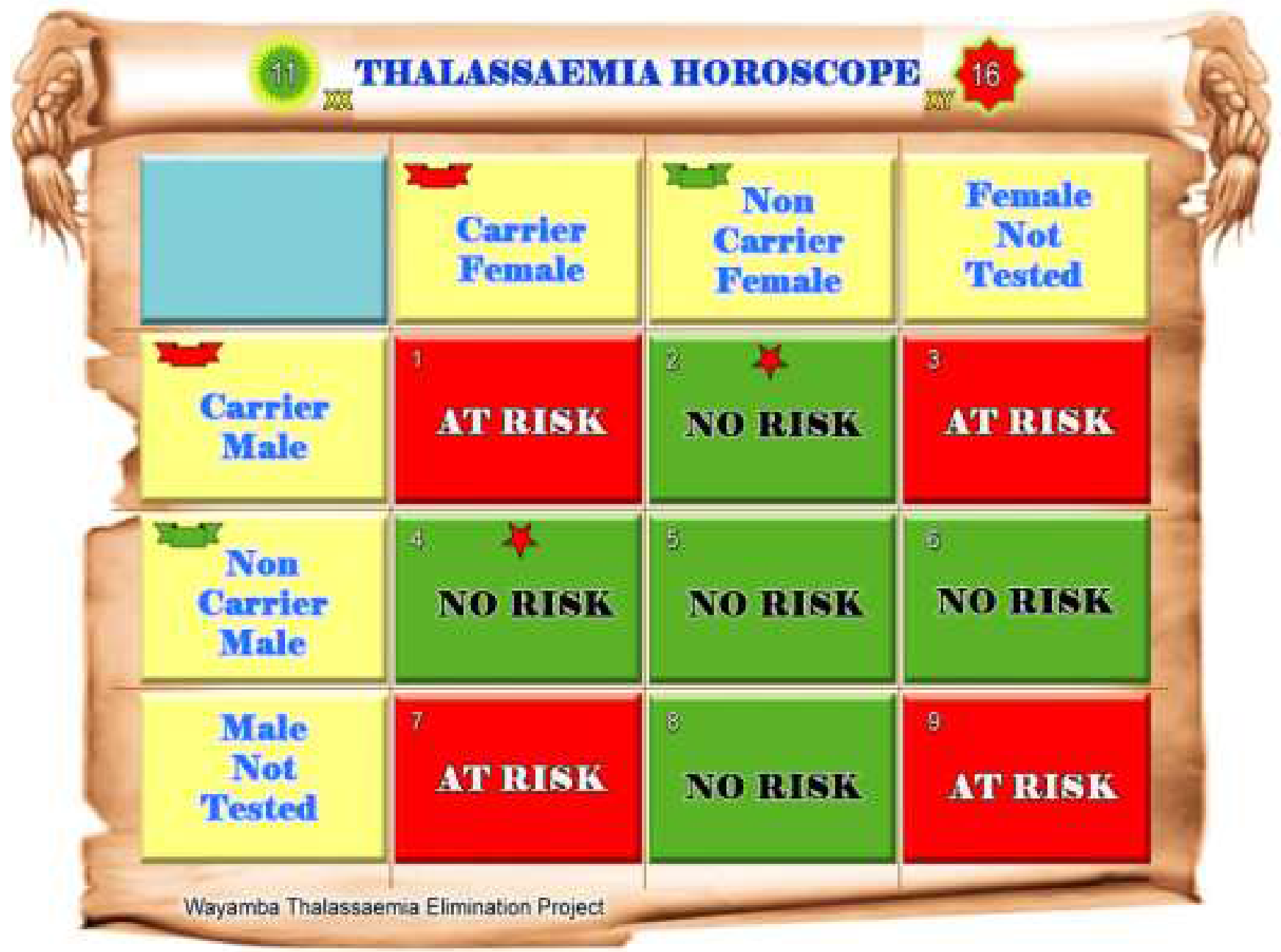

Figure 1 Pictorial depiction of the risks of range of combinations of pairs in a proposed couple. 


\section{References}

Pemawardhena A, De Silva S, Arambepola M, Olivieri N, Merson L, et al. (2004) Thalassemia in Sri Lanka: a Progress report, Human Molecular Genetics 13: 203-206.

Health Ministry records an increase in thalassemia patients in Sri Lanka ColomboPage Sri Lanka Internet News Paper (2013) http:// www.colombopage.com/archive_13B/Dec16_1387175876JV.php.

Peiris S, Hewapathirana R, Rampatige R, Hanifa A (2010) National Thalassaemia eRegistry: using IT for effective health resource management eHealth Sri Lanka 1: S15.

4 Maheepala P (2014) Thalassaemia-The Current Status in Sri Lanka, International Conference on Birth Defects 2014, Genes, Genome and Human Malformations.

Khorasani G, Kosaryan M, Vahidshahi K, Shakeri S, Nasehi MM (2008) Results of the national program for prevention of beta-thalassemia major in the Iranian Province of Mazandaran, Hemoglobin 32: 263-271.

5 Ansari SH, Shamsi TS (2010) Thalassaemia Prevention Programme. Haematology Updates 23-28.
Mudiyanse RM (2006) Thalassemia treatment and prevention in Uva Province Sri Lanka: Public opinion survey. Hemoglobin 30: 275-289.

8 Cousens NE, Gaff CL, Daltycki MB (2010) Carrier screening for betathlassaemia: a review of international practice. Eur J Hum Genet 18 : 1077-1083.

9 Fucharoen S, Winichagoon P (2007) Prevention and control of thalassemia in Asia, Asian Biomedicine 1: 1.

10 Bozkurt G (2007) Results from the north Cyprus thalassemia prevention program. Hemoglobin 31: 257-264.

11 Model B, Darlison M (2008) Global epidemiology of haemoglobin disorders and derived service indicators. Bulletin of the World Health Organization 86: 480-487.

12 Ginsberg G, Tulchinsky T, Filon D, Goldfarb A, Abramov L, et al. (1998) Cost-benefit analysis of a national thalassaemia prevention programme in Israel. J Med Screen 5: 120-126.

13 Ostrowsky JT, Lippman A, Scriver CR (1985) Cost-benefit analysis of a thalassemia disease prevention program, Am J Public Health 75: 732-737 